\title{
A criação de sinais em libras por meio de pessoas ouvintes
}

\author{
Andréa dos Guimarães de Carvalho ${ }^{1}$
} Adriell Fonseca Santos ${ }^{2}$

\begin{abstract}
Resumo
Este trabalho traz reflexões sobre as discussões bibliográficas presentes na literatura das línguas de sinais, no caso da Libras, sobre os paradigmas que envolvem o processo de criação de sinais por seus usuários, pessoas surdas e ouvintes, habilitados para criarem sinais que são validados pela comunidade surda. Busca-se saber a participação efetiva da pessoa ouvinte nesse processo. Para tanto, são levantados, brevemente, alguns elementos motivacionais, linguísticos e socioculturais na formação desses sinais, assim como os aspectos relacionados aos parâmetros que constituem os sinais do léxico da língua, seu contexto de uso e a construção do significado desse sinal, seja no âmbito da arbitrariedade ou da iconicidade nesse processo de formação. A metodologia utilizada foi a analítica qualitativa de investigação bibliográfica com a finalidade de conhecer as possíveis pesquisas nessa área de criação de sinais em Libras. Como resultados da pesquisa, percebe-se que ainda temos pouco conteúdo científico sobre o assunto, dificultando assim a compreensão do envolvimento da pessoa ouvinte na criação de sinais, pode-se concluir, no entanto, que surdos e ouvintes são usuários da Libras e fazem parte da comunidade surda.
\end{abstract}

Palavras-chave: criação, formação, sinais, processo, libras, língua, surdos, ouvintes, processo.

\section{Creating signs in libras through hearing people}

\begin{abstract}
This work brings reflections on the bibliographic discussions present in the literature of sign languages, in the case of Libras, on the paradigms that involve the process of creating signs by its users, deaf and hearing people, qualified to create signs that are validated by the deaf community. We seek to know the effective participation of the hearing people in this process. Therefore, some motivational, linguistic and sociocultural elements are briefly raised in the formation of these signs, as well as the aspects related to the parameters that constitute the signs of the language lexicon, its context of use and the construction of the meaning of this sign, whether in the scope of arbitrariness or iconicity in this formation process. The methodology used was the qualitative analytical of bibliographic investigation in order to know the possible researches in this area of sign creation in Libras. As a result of the research, it is clear that we still have little scientific content on the subject, thus making it difficult to understand the hearing person's involvement in the creation of signs, it can be concluded, however, that deaf and hearing people are Libras users and do part of the deaf community.
\end{abstract}

Keywords: creation, formation, signs, process, Libras, language, deaf, hearing.

\section{Introdução}

Sabe-se que a necessidade de conscientização e informação sobre a criação de sinais na Libras (Língua Brasileira de Sinais) é fundamental. A ausência do significado de um sinal (item lexical) para um determinado contexto, em língua de sinais, pode ser prejudicial à

\footnotetext{
1 Doutora em Letras/Linguística pela Universidade de Brasília (UnB); Professora efetiva da Universidade Federal de Goiás (UFG). E-mail: andrea.cenaudio@gmail.com.

${ }^{2}$ Especialista em Linguística das Línguas de Sinais pela Universidade Federal de Goiás; Professor de Libras na Esfera Estadual das Escolas Militares de Goiás. E-mail: adriellfonseca700@gmail.com.
} 
comunicação. Surdos e ouvintes, competentes linguisticamente, devem ser motivados à produção de sinais, pois a Libras é uma língua que pertence a todos os seus usuários e tem como objetivo permitir a comunicação, interação social, acesso à informação e autonomia de conhecimento que favorecem o desenvolvimento de um cidadão ativo na sociedade atual.

Surdos e ouvintes necessitam ter o domínio do idioma Libras, ou seja, ser capacitados linguisticamente, ter o conhecimento cultural, social e usual da Língua de Sinais, nos diversos contextos existentes no cotidiano, para produzir sinais. A limitação em algum desses conhecimentos desencadeia o mau uso e o desrespeito à estrutura linguística que aborda os elementos constitutivos da Libras, que se torna uma mera tentativa de comunicação com os surdos (QUADROS, 2019).

É válida a reflexão sobre a necessidade de criação de sinais. Deve-se observar o campo linguístico: a fonologia, morfologia, sintaxe, semântica e o seu uso contextual no dia a dia. Partindo desse ponto e percebendo que a Libras é uma língua viva e atual, é necessário se ter uma reflexão sobre como os usuários criam os sinais e como os utilizam para promover um significado que desencadeia uma compreensão comunicativa, seja entre emissor e receptor, ou mesmo para transmitir uma informação intuitiva. Isso demonstra que não se trata de uma criação limitada somente à pessoa surda, mas de conhecedores da língua, a Libras e seu uso no cotidiano.

Com essa finalidade, muitos precisam compreender como se dá o processo de criação de um sinal, conhecer os aspectos linguístico-gramaticais envolvidos, principalmente, no campo semântico-pragmático e seus impactos causados no contexto sócio-histórico-cultural dos usuários da Libras.

\section{O processo de criação de sinais em libras}

Sabe-se que a comunicação por meio das mãos vem desde a Pré-história e, com o passar do tempo, foi substituída pela oralidade. Naquele momento, as mãos foram utilizadas para manusear ferramentas. Segundo Silva (2019), por esse fator, houve a predominância da língua oral, e os surdos foram excluídos da sociedade.

Ao longo da Idade Antiga, Média e Moderna, pôde-se observar que os surdos não eram considerados seres com competências iguais aos demais seres humanos, pois não 
falavam e, portanto, segundo a crença da época, eram incapazes de formularem pensamentos lógicos como o esperado para as pessoas que se comunicavam através da fala.

Para os gregos antigos, por exemplo, a fala era símbolo de conhecimento e reconhecimento social. Da mesma forma, na Roma Antiga e na Idade Média, os surdos não tinham direitos e eram marginalizados. Segundo Silva (2019), somente na Idade Moderna é que os surdos começaram a ser vistos de uma nova perspectiva. Pedro Ponce, um monge beneditino espanhol, foi o primeiro professor de surdos. Ele criou um manual que ensinava técnicas de oralização, ensinando os surdos da sua época a oralizar, sinalizar, ler e escrever, comprovando a capacidade de aprendizagem da pessoa surda.

Os autores mencionam o professor francês Charles-Michel de l'Épée como importante precursor no desenvolvimento das Línguas de Sinais. L’Épée foi o primeiro a criar, no século XVIII, um alfabeto de sinais para alfabetizar surdos em sua escola no ano de 1755.

Tem-se que a LSF - Língua de Sinais Francesa foi desenvolvida por l'Épée e influenciou de maneira positiva para criação da Língua Brasileira de Sinais no século XVIII.

Para Silva (2019), Ernest Huet, professor francês, foi o pioneiro na educação de surdos. Ele se mudou para o Brasil em 1855 por convite do imperador D. Pedro II. Huet contribui para a criação da primeira escola de educação de surdos, chamada de Imperial Instituto de Surdos-Mudos. Essa escola construiu bases para a formulação da Libras a partir de sinais já utilizados no Brasil.

A Língua Brasileira de Sinais é uma língua visual-espacial usada no Brasil pelas comunidades surdas espalhadas por todo o território nacional. Se expressa com o corpo, as mãos, o uso dos espaços próximos ao corpo e a visão para ser produzida e percebida. Segundo Quadros (2019), a Libras é uma língua dotada de todos os níveis de análise linguística, como fonemas e padrões prosódicos. Suas palavras combinam para formar enunciados e estes apresentam proposições que podem ser analisadas no campo semântico e pragmático; e seus usos apresentam questões de ordem sociolinguística.

No Brasil, de acordo com a lei $\mathrm{n}^{\mathrm{o}} 10.436$, de 24 de abril de 2002, a Libras possui estrutura gramatical própria, possibilitando, assim, o desenvolvimento linguístico da pessoa surda, favorecendo o seu acesso aos conhecimentos existentes na sociedade (BRASIL, 2002, p. 1). 
Na década de 1960, William Stokoe reconheceu a Língua de Sinais como língua. Stokoe (1960) provou que a língua satisfazia a todos os critérios linguísticos de uma língua comum, como a capacidade de gerar um número infinito de proposições e corresponder às expressões desejadas pelo sinalizante.

Naquela época, essa língua era uma espécie de código gestual e servia apenas como um apoio à comunicação. Segundo Sacks (1998), Stokoe observou que a Língua de Sinais era complexa e que tinha uma estrutura própria, ou seja, uma gramática própria, com localização, movimento e configurações de mãos, importantes para a efetivação da comunicação.

Ressalta-se que as Línguas de Sinais não são universais, cada país possui sua própria língua com estrutura gramatical própria. Os usuários de uma língua de sinais podem discutir sobre qualquer âmbito do saber, inclusive produzir arte, como poesias e teatro.

As línguas de sinais possuem um papel determinante para a vivência dos usuários delas em um contexto social. De acordo com Quadros (2006), as línguas expressam sua capacidade específica em um grupo social, possibilitando aos seres humanos a interação e expressão de culturas, valores e padrões sociais.

Compreende-se que todas as línguas de sinais têm uma estrutura gramatical própria e estudos linguísticos que fazem parte de suas composições. A estrutura da Libras, por exemplo, é dotada de parâmetros que formam sinais ou itens lexicais. A área que estuda o léxico é a fonética. Conforme dispõe Quadros (2019), a fonética das línguas vai se ocupar de todas as unidades de produção e percepção de articuladores manuais e não manuais, manifestada através da expressão física. Um sinal é formado a partir da combinação de cinco parâmetros:

1) Configuração de mãos: é a forma que a mão assume ao realizar o sinal. Pode ser uma letra do alfabeto manual ou outras formas feitas pela mão dominante (mão direita para os destros, mão esquerda para os canhotos), ou pelas duas mãos do sinalizador.

2) Ponto de articulação: é o lugar onde a mão dominante realiza o sinal, podendo tocar alguma parte do corpo ou estar perto dela, ou estar em frente ao corpo do emissor, no chamado espaço de enunciação (do meio do corpo até a cabeça).

3) Orientação: é a direção para a qual a palma da mão aponta na produção do sinal. Sabe-se que existem seis tipos de orientação da palma da mão: para cima, para baixo, para o corpo, para frente, para a direita ou para a esquerda. 
4) Movimento: os sinais podem ter movimento ou não. Os movimentos podem envolver várias formas e direções, podem estar nas mãos, pulsos e antebraço. Os movimentos podem ser classificados por tipo, direcionalidade, maneira e frequência. Quanto à direcionalidade, os movimentos podem ser unidirecionais, bidirecionais ou multidirecionais. A maneira é a categoria que descreve a qualidade, a tensão e a velocidade do movimento. A frequência refere-se ao número de repetições de um movimento.

5) Expressão facial e/ou corporal ou expressões não manuais: muitos sinais, além dos quatro parâmetros mencionados acima, têm em sua configuração também como traço diferenciador a expressão facial e/ou corporal, tais como os sinais de DIFÍCIL e RISADA. Esses são movimentos da face, dos olhos, da cabeça ou do tronco. As expressões não manuais marcam os tipos de frases: interrogativa, exclamativa, negativa, afirmativa etc.

No entanto, não é suficiente compreender apenas a fonologia e fonética, como também o estudo da morfologia. Esta última estuda a estrutura interna das palavras/sinais e os processos de formação e transformação de novos sinais, que podem ser realizados pelos processos de derivação, composição e flexão. Os níveis semântico, com foco no estudo individual de um sinal ou numa frase, e pragmático que se refere ao estudo do significado do discurso formado pela combinação dessas palavras/sinais, isto é, do agrupamento destes nas sentenças e que descreve a significação pretendida no texto e no contexto, ou seja, permeia o nível morfossintático em interface com a sintaxe. Segundo Quadros (2019), uma descrição semântica pode ser feita no nível da palavra ou sinal, da sentença e do discurso e compreende sequencialidade e simultaneidade, característica da modalidade de uma língua de sinal, inclusive da Libras.

Outro estudo linguístico relevante é a sintaxe. A sintaxe analisa a combinação de sinais para a formação de estruturas frasais. De acordo com Quadros (2019), a Libras possui uma ordem básica das palavras/sinais que é SVO (sujeito-verbo-objeto). Segundo a autora, a ordem básica é aquela na qual identificamos a presença de um sujeito, de um verbo e de um objeto realizados, sem marcações não manuais específicas. Contudo, há outras marcações sintáticas, como por exemplo, a SOV (sujeito-objeto-verbo), OSV (objeto-sujeito-verbo), entre outras.

Sem saber o sentido, significado e aplicação dos sinais no dia a dia, é impossível a comunicação em Língua de Sinais. Por isso, o estudo da Semântica torna-se primordial para 
análise e aplicação da língua como, também, o estudo da pragmática, que cuida da estrutura discursiva das palavras/sinais, obtendo coesão naquilo que se expressa ou se escreve.

Dessa maneira, a Libras é, portanto, uma combinação de todos esses estudos e elementos que formam as palavras/sinais e estas formam as frases em um contexto. No entanto, nem todos os sinais apresentam todos os elementos. Existem sinais, por exemplo, sem movimento e/ou sem expressão facial e há sinais feitos apenas com expressões não manuais.

Observados esses elementos constitutivos da Libras, pode-se analisar a criação de sinais na comunidade surda. Interessante observar que comunidade surda engloba não somente surdos, mas também sujeitos ouvintes, usuários dessa língua. Segundo Strobel (2009), povo surdo é um grupo de sujeitos com suas tradições e costumes, e comunidade surda é um grupo formado por surdos e ouvintes, onde ambos participam ativamente e compartilham os mesmos interesses em comum.

Logo, Strobel (2009) não discute, a priori, a quem se destina, especificamente, o criador dos sinais que constituem o léxico da Libras, mas demonstra uma confraternização mútua e condicionada que emerge de dentro de uma comunidade onde todos têm em comum o uso de uma mesma língua, a Libras.

Souza e Gediel (2017) fizeram uma pesquisa para verificar como os surdos atribuem sinais para nomes próprios. Segundo eles, existem dois fatores referentes aos sinais para nomes próprios: a) a predominância do uso do parâmetro $\mathrm{CM}$ do alfabeto datilológico, referente à letra inicial do nome da pessoa em Língua Portuguesa escrita, geralmente criado por um surdo; b) o outro corresponde à criação de sinais a partir do léxico das Línguas de Sinais, usando classificadores e configurações de mãos apropriadas e convencionadas na comunidade surda. Descobriram ainda que o processo de nomeação das pessoas surdas é um elemento importante da Libras, pois é a forma como eles se reconhecem e são reconhecidos pelos demais sinalizantes, estabelecendo assim, uma forma de batismo nessa comunidade. Interessante destacar aqui que em toda a literatura estudada somente esses autores relataram o papel do surdo na criação de um sinal-nome para integrantes da comunidade, talvez com uma ideia de empoderamento cultural, mas não descartam a participação do ouvinte, integrante dessa comunidade e usuário da Libras nesse processo. 


\section{A Iconicidade e arbitrariedade no processo de criação de sinais em libras}

A Iconicidade nas línguas de sinais apresenta uma característica semelhante ao das demais línguas, isto é, ao que o ícone tem em comum na forma que o objeto ou coisa, animado ou inanimado representa. Por ser uma língua de modalidade visuoespacial, a iconicidade é um dos elementos que predomina na Libras, pois a relação entre a "forma" e o "sentido" é algo visível na forma ou ação.

Taub (2012) destaca que a iconicidade existe em todos os tipos de língua e é uma forma normal de criar itens linguísticos em que estruturas icônicas convencionais emergem por meio da repetição de sobreposição de imagens mentais e seus referentes.

Segundo Teixeira (2013), dois exemplos que podemos destacar na Libras são os sinais "árvore" e "cadeira", constituídos a partir de características da imagem dos objetos aos quais se referem. Enquanto o primeiro lembra a imagem do tronco e das folhas de uma árvore, o segundo lembra as pernas de uma pessoa, representadas pelos dedos indicador e médio, sentada no objeto em análise, conforme as figuras abaixo.

Figura 1: Sinais de ÁRVORE e CADEIRA

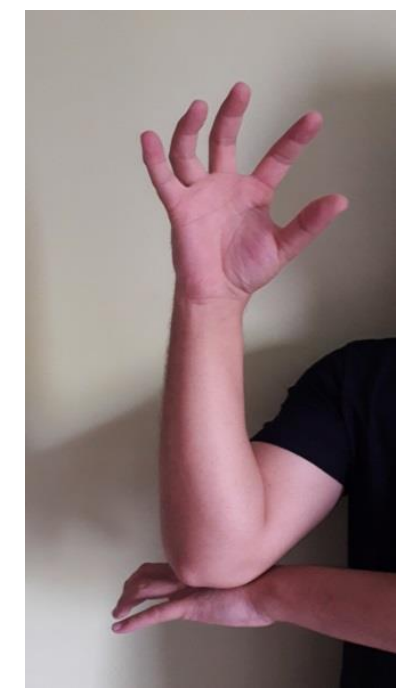

Foto 1: ÁRVORE.

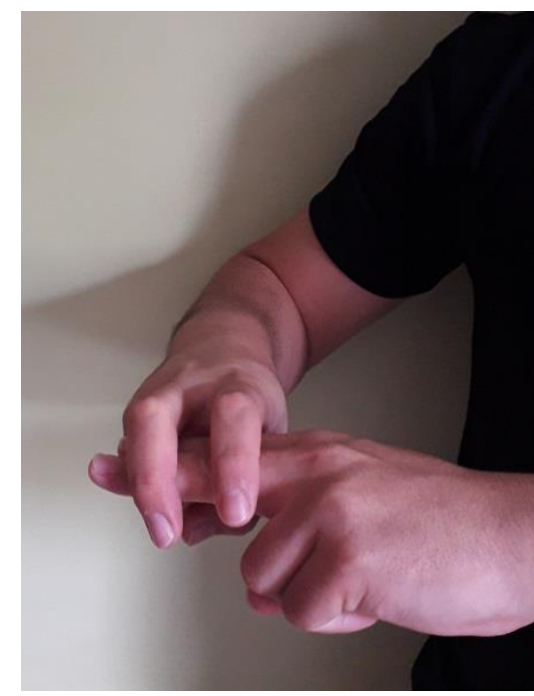

Foto 2: CADEIRA.

Fonte: Produzido pelo próprio autor.

De acordo com Charles e Liberato (2010), a modalidade gestual-visual-espacial pela qual a Libras é produzida e percebida pelos surdos decorre de sua natureza linguística, expressando um sinal pelas características da realidade a que se refere, mas isso não é uma 
regra. A grande maioria dos sinais da Libras é arbitrária e não possui relação de semelhança com seu referente.

Uma das propriedades básicas de uma língua é a arbitrariedade existente entre significante e referente. De acordo com Teixeira (2013), a ideia de arbitrariedade se relaciona com a ideia de convenção: enquanto a palavra "cadeira" é icônica na língua de sinais, na língua portuguesa, por exemplo, ela é arbitrária, pois só recebe esse nome devido a uma convenção que estabelece esse conceito e não porque há uma relação entre o som da palavra e o objeto que ela designa. Outro exemplo citado pela autora, no caso da Libras, ocorre com as palavras: "biscoito" e "desculpar". Segundo ela, esses sinais não têm seus constituintes influenciados pela imagem dos objetos aos quais eles se referem. Eles mostram que, mesmo a libras sendo uma língua de forte motivação icônica, alguns dos seus sinais são arbitrários. A figura 2 confirma a descrição acima.

\section{Figura 2: Sinais BISCOITO e DESCULPAR}

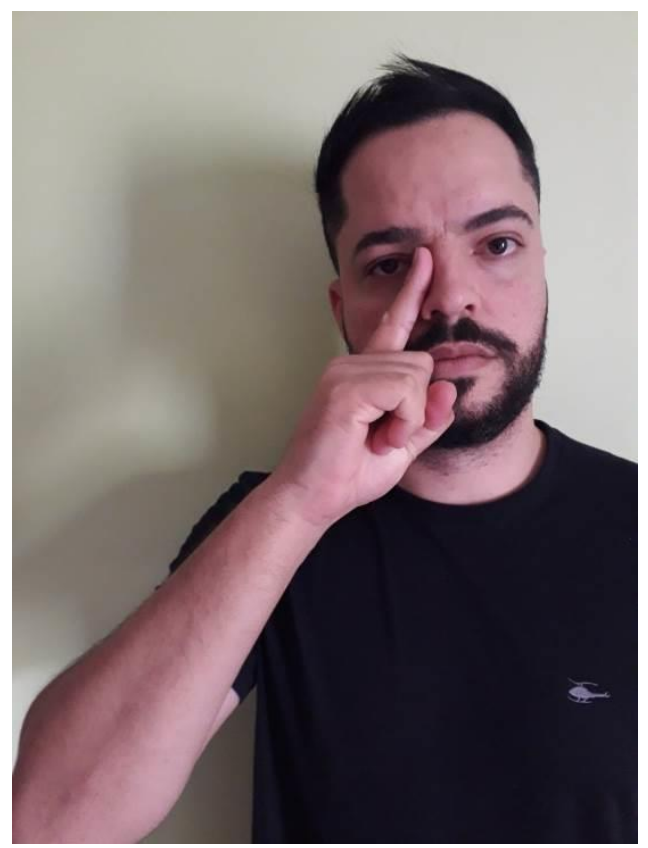

Foto 3: BISCOITO

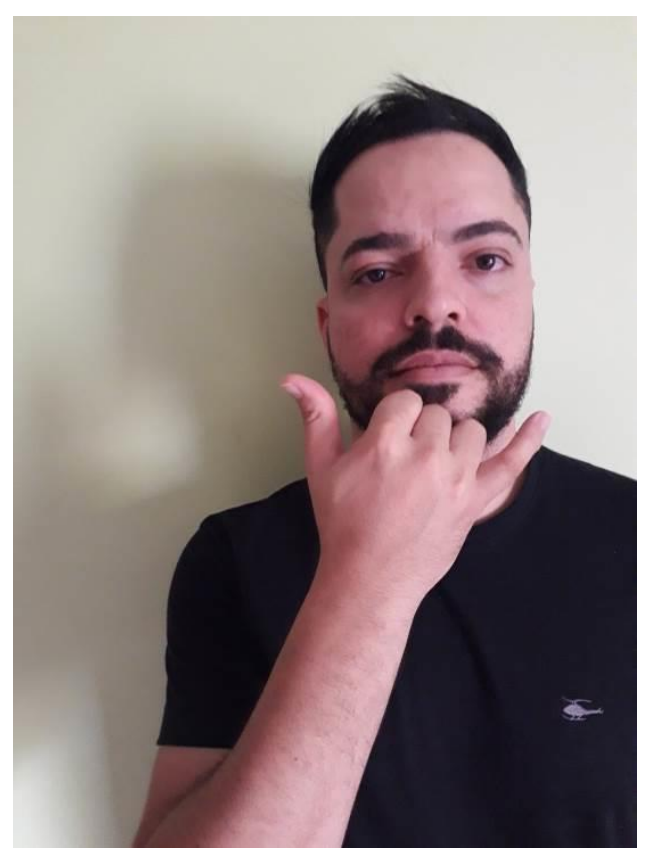

Foto 4: DESCULPAR

Fonte: Produzido pelo próprio autor. 
203 Polyphonía, v. 32/2, jul./dez. 2021

\section{O papel do contexto e a construção do significado}

Sabe-se que o contexto é a relação entre a fala ou texto e a situação em que ocorre dentro do texto ou situação apresentada, contribuindo para o seu significado no discurso. Bernardino (1999) discorre sobre a importância e relevância de o receptor da mensagem estar ciente daquilo que permeia os arredores do objeto discutido em uma cena, sendo este chamado de contexto intrínseco ao processo. Acrescenta-se também o conhecimento de mundo do receptor, todas as experiências vivenciadas naquele momento, sendo este contexto denominado de incidental.

A mensagem pode ser interpretada de forma distorcida por causa do entendimento da mensagem transmitida ao receptor. Por esse fator, a compreensão da mensagem pelo emissor precisa ter três evidências durante o processo: copresença física, copresença linguística e pertencer à mesma comunidade. A copresença física garante que os interlocutores tenham conhecimento do evento; a copresença linguística garante que os interlocutores falem sobre o mesmo assunto, usem a mesma linguagem; o pertencimento à mesma comunidade garante que eles estão falando de algo que elas entendem com o mesmo significado (Bernadino, 1999).

O desafio do contexto é garantir que os interlocutores em um discurso estejam falando sobre um mesmo assunto e utilizando a mesma linguagem, bem como, pertençam à mesma comunidade. Tudo isso para que possa haver o entendimento do contexto.

De acordo com Lima e Aragão Neto (2015), em um processo centrado no contexto, os ouvintes usam a situação e o contexto da sentença para a compreensão do que o falante quer dizer. Logo, quanto mais informações o contexto provê, maior é a confiança conseguida na construção do significado. Portanto, a construção do significado não é realizada a partir apenas do conhecimento do léxico e da gramática, ocorre através da relação de processos cognitivos que promovem a compreensão do signo linguístico e da criação do significado baseado na perspectiva de uso linguístico.

\section{Considerações Finais}

Diante do exposto, constata-se com esta pesquisa bibliográfica que o processo de criação de sinais por usuários da Língua Brasileira de Sinais ocorre independente da 
predominância do aspecto sociocultural de um sujeito que contempla e contribui ativamente na comunidade surda. Logo, segundo a literatura, parece haver uma participação mútua e reflexiva coletiva entre surdos e pessoas ouvintes na criação de sinais, uma vez que implica convencionalmente um processo e o desenvolvimento de como ele se aplica na comunidade como um todo, já que tanto surdos quanto ouvintes são usuários da Libras e fazem parte da comunidade surda.

O único caso encontrado na literatura, durante o estudo, foi o de Souza e Gediel (2017), que apresentaram a existência de fatores que influenciam e atribuem critérios para a criação de sinais para nomes próprios, por estarem enraizados nas singularidades da cultura surda, em que se destaca a língua como elemento cultural comum entre a comunidade surda.

Inclusive sobre cultura surda, que implica singularidades do sujeito surdo, sobre a criação de sinais, Strobel (2009) não discute a quem se destina a responsabilidade de criar os sinais que constituem o léxico da Libras, mas demonstra uma confraternização mútua e condicionada dentro de uma comunidade em que todos têm o uso de uma mesma língua em comum, a Libras.

Observa-se que ainda há pouco conteúdo científico sobre o assunto da pesquisa. Sendo assim, pretende-se avançar a pesquisa, colocando em prática tudo o que foi visto na bibliografia, aprofundando os dados a serem coletados, percebendo se vem acontecendo ou mudando a criação de sinais; se houve modificação no processo de criação de sinais e possível parcela efetiva da participação da pessoa ouvinte.

\section{Referências}

BERNARDINO, E. L. A construção da referência por surdos na LIBRAS e no português escrito: a lógica no absurdo. Dissertação (Mestrado em Letras) - UFMG, Minas Gerais, 1999. Disponível em: http://www.letras.ufmg.br/profs/elidea/data1/arquivos/Bernardino-Elidea1999.pdf. Acesso em: 28 set. 2013.

BRASIL. Lei $n^{o}$ 10.436, de 24 de abril de 2002. Dispõe sobre a Língua Brasileira de Sinais Libras. Disponível em: http://www.planalto.gov.br/ccivil_03/leis/2002/110436.htm. Acesso em: 10 de maio de 2020.

QUADROS, R. M. Libras. São Paulo: Parábola, 2019. 
QUADROS, R. M; KARNOPP, L. B. Língua de sinais brasileira: estudos linguísticos. Porto Alegre: Artmed, 2004.

QUADROS, R.M; SCHMIEDT, M. L. P. Língua Brasileira de Sinais. Porto Alegre: Artmed, 2006, p. 13.

LIBERATO, CHARLES. Iconicidade e Arbitrariedade. Disponível em: http://charleslibras.blogspot.com/2010/04/iconicidade-e-arbitrariedade.html. Acesso em: 02 maio de 2020.

LIMA, M. A. C. B; ARAGÃO NETO, M. M. Aspectos semânticos e pragmáticos da Libras. Disponível em: http://www.coipesu.com.br/upload/trabalhos/2015/2/aspectos-semanticos-epragmaticos-da-libras-abordagem-no-contexto-sala-de-aula.pdf. Acesso em: 20 abril de 2020.

SACKS, Oliver. Vendo vozes: uma viagem ao mundo dos surdos. Trad. Teixeira Motta. São Paulo: Companhia das Letras, 1998.

SILVA, Daniel Neves. Língua Brasileira de Sinais (Libras). Disponível em: https://brasilescola.uol.com.br/educacao/lingua-brasileira-sinais-libras.htm. Acesso em: $18 \mathrm{de}$ fevereiro de 2020.

SOUZA, Isabelle Lima; GEDIEL, Ana Luíza. Os sinais dos surdos: uma análise a partir de uma perspectiva cultural. Disponível em: https://www.scielo.br/scielo.php?pid=S010318132017000100163\&script=sci_abstract\&tlng=pt. Acesso em: 02 de maio de 2020.

STROBEL, Karin. História de Educação dos Surdos. Disponível em: http://www.libras.ufsc.br/colecaoLetrasLibras/eixoFormacaoEspecifica/historiaDaEducacaoD eSurdos/assets/258/TextoBase_HistoriaEducacaoSurdos.pdf. Acesso em: 10 de dezembro de 2019.

TAUB, S. Iconicity and metaphor. In: PFAU, R.; STEINBACH, M.; WOLL, B. (Orgs.). Sign Language: an International Handbook. Berlin: Mouton de Gruyter, 2012. p. 388- 412.

TEIXEIRA, Vanessa Gomes. A Iconicidade e Arbitrariedade na Libras. Disponível em: http://www.filologia.org.br/vii_sinefil/COMPLETOS/A\%20iconicidade\%20e\%20arbitrarieda de\%20na\%20Libras\%20-\%20VANESSA.pdf. Acesso em: $1^{\circ}$ de abril de 2020. 